\title{
Topotaxial Hydrothermal Anion Exchange in the Apatite Structure
}

\author{
J.C. Rendon-Angeles ${ }^{1 *}$, K. Yanagisawa ${ }^{2}$, N. Ishisawa ${ }^{3}$, S. Oishi ${ }^{4}$ \\ (*Corresponding author: jcarlos@saltillo.cinvestav.mx) \\ ${ }^{1}$ Res. Inst. Advanced Studies, CINVESTAV Campus-Saltillo, Ramos Arizpe Coahuila 25900, México. \\ ${ }^{2}$ Res. Lab. Hydrothermal Chemistry, Kochi University, 2-5-1 Akebono-cho, Kochi, Kochi 780-8520, Japan. \\ ${ }^{3}$ Ceramic Res. Lab., Nagoya Institute of Technology, 10-6-29 Asahigaoka, Tajimi, Gifu 507-0071, Japan. \\ ${ }^{4}$ Dep. Environmental Sci. Technol., Faculty of Engineering, Shinshu University, Nagano 380-8553, Japan.
}

Keywords: Apatite, Anion exchange, Chlorapatite, Fluorapatite, Hydroxyapatite

Abstract: Calcium chlorapatite single crystals were converted to hydroxyapatite single crystals by the hydrothermal treatments at $500^{\circ} \mathrm{C}$ for $12 \mathrm{~h}$ in a $6.25 \mathrm{M} \mathrm{KOH}$ solution. The mechanism of this topotaxial anion exchange is considered to be dissolution-precipitation of clusters. Calcium chlorapatite and hydroxyapatite single crystals were also converted to fluorapatite single crystals by the hydrothermal treatments at $500^{\circ} \mathrm{C}$ in a $5 \mathrm{M} \mathrm{KF}$ solution but that of fluorapatite to hydroxyapatite proceeded by ordinary dissolution and precipitation of ions. The effects of metal ions in chlorapatite and the details of the reaction process were discussed.

(Received July 1, 2004; Accepted August 27, 2004)

\section{INTRODUCTION}

Apatite and their related solid solutions are practically found in all geologic environments, and the major constituent of the large mineral apatite family is calcium fluorapatite, $\left(\mathrm{Ca}_{10}\left(\mathrm{PO}_{4}\right)_{6} \mathrm{~F}_{2}\right.$ (hereafter refereed as $\mathrm{CaFAp}$ ) [1-3]. Another member of the apatite group is calcium hydroxyapatite $\left(\mathrm{Ca}_{10}\left(\mathrm{PO}_{4}\right)_{6}(\mathrm{OH})_{2}\right.$ (hereafter refereed as CaHAp), which is the principal inorganic component of human bones and hard tissues. Therefore, CaHAp has been the research subject of extensive biological and physico-chemical evaluations [4]. A great interest on compositional and structural evaluations had been focused on biological and geological apatite and its related calcium phosphate compounds; because each member of the apatite mineral specie is apt to uptake several foreign cations or anions in its hexagonal cell lattice [5-9]. Thus, several isomorphic substitutions had been reported to occur at the lattice leading to the formation of isomorphs or solid solutions apatites.

This property of the apatite is based on its crystalline structure $\left[\mathrm{M}\left(\mathrm{ZO}_{4}\right)_{3} \mathrm{X}_{2}\right]$, which has the ability to incorporate several cations or anions at both lattice sites. Among the substitution of metal ions in the $\mathrm{M}$ site, metal ions such as $\mathrm{Sr}^{+2}, \mathrm{Ba}^{+2}, \mathrm{~Pb}^{+2}, \mathrm{Zn}^{+2}$ and $\mathrm{Cd}^{+2}$ can replace $\mathrm{Ca}^{+2}$ at their lattice positions [4], while the common anionic replacements in the apatite structure involves $\mathrm{F}^{-}$by $\mathrm{OH}^{-}, \mathrm{Cl}^{-}$or $\mathrm{I}^{-}$, and $\mathrm{PO}_{4}^{-}$by $\mathrm{AsO}_{4}^{-}$or $\mathrm{VO}_{4}^{-}[10]$. The present review intended to provide detailed features of the anion exchange process under hydrothermal conditions, as well as, some experimental aspects which have an influence on the topotaxial ion exchange ability of the apatite structure, such as the effect of the metal ion in the alkaline solution and in the apatite structure.

\section{TOPOTAXIAL SOLID STATE ION EXCHANGE}

In the synthetic apatite, the topotaxial ion exchange reaction was found in 1967 by Elliot and Young [11]. Their preliminary attempts have been aimed to evaluate structural aspects of CaHAp single crystals by X-Ray and neutron diffraction methods, which require large scale crystals (millimetre order) for the analysis. They showed that the solid state ion exchange of chloride ions $\left(\mathrm{Cl}^{-}\right)$by hydroxyl ions $\left(\mathrm{OH}^{-}\right)$in large calcium chlorapatite single crystals $\left(\mathrm{Ca}_{10}\left(\mathrm{PO}_{4}\right)_{6} \mathrm{Cl}_{2}\right.$, here after refereed as CaClAp), which were successfully grown by the flux method.

In the solid state, the uptake of $\mathrm{OH}^{-}$and the loss of $\mathrm{Cl}^{-}$were investigated using synthetic CaClAp single crystals, spherical crystals $0.4 \mathrm{~mm}$ in size, which were treated in a water vapour atmosphere at a temperature of $1300^{\circ} \mathrm{C}$ for 2 weeks. Under these conditions the conversion from CaClAp to CaHAp was completed. Preliminary naked eye observations of the remained reaction products demonstrated that the converted crystals retain their original shape and dimensions. Furthermore, neutron activation analysis and X-ray diffraction (XRD) precession photographs showed that the reaction products were essentially single crystals of CaHAp, although a small amount of $\mathrm{Cl}^{-}$ remained in converted crystals. However, further details regarding the inner microstructure of the converted CaHAp single crystals were not provided by the authors. The results obtained by Elliot and Young [4] reported the first evidence for the topotaxial ion exchange in the apatite structure under the solid state conditions. In contrast, a large number of apatite isomorphs or apatite solid solutions were 
Rendon-Angeles JC, Yanagisawa K, Ishisawa N, Oishi S prepared by solid state reactions that did not include the ion exchange mechanism [6-12].

Other investigations have been directed towards to clarify some aspects of the ion exchange mechanism, ion diffusion coefficients and morphological features of the crystals treated under solid state conditions [13] Brenan has carried out a series of experiments to evaluate the exchange of $\mathrm{F}^{-}, \mathrm{Cl}^{-}$and $\mathrm{OH}^{-}$in natural CaFAp single crystals at $1200^{\circ} \mathrm{C}$ with low $(1 \mathrm{~atm})$ and high pressure $(1 \mathrm{GPa})$. The replacement of $\mathrm{F}^{-}$by $\mathrm{Cl}^{-}$ proceeds by atomic diffusion along the $c$ and $a$ axis of the hexagonal lattice of the CaFAp. Diffusion coefficients of $\mathrm{Cl}^{-}, \mathrm{F}^{-}$or $\mathrm{OH}^{-}$were calculated from the concentration EDS profiles, which were determined parallel to $a$ and $c$-axis of gem-quality hexagonal single crystals. These results showed that the ion exchange process depends on the direction of the hexagonal lattice cell, because it proceeds rapidly parallel to the $c$-axis rather than through the $a$-axis. The diffusion coefficient along the $c$-axis was further increased at high pressure (1 $\mathrm{GPa})$ even under hydrothermal conditions. The uptake of $\mathrm{Cl}^{-}$and $\mathrm{OH}^{-}$ was completed at $1200^{\circ} \mathrm{C}$ for a time as short as $12 \mathrm{~h}$ under high pressure.

On the other hand, this peculiar conversion of CaFAp by CaHAp, implies the replacement of small $\mathrm{F}^{-}$(ionic radius of $0.132 \mathrm{~nm}$ ) by larger $\mathrm{Cl}^{-}$(ionic radius of $0.181 \mathrm{~nm}$ ) or $\mathrm{OH}^{-}$(ionic radius of $1.68 \AA$ ), which might result in the expansion of the volume cell of the hexagonal lattice of the apatite. Thus, morphological aspects revealed on the converted part of the CaFAp single crystals are mainly related with the formation of microcracks. The microcracks were formed in order to compensate the large expansion along the $a$-axis which occurs as a result of the conversion. Therefore, these defects made the hexagonal gem quality single crystal to loose its original shape and dimensions. Both structural analysis and the microstructure observations bear the first evidence of the effect of the structural differences associated with the anion size on the topotaxial ion exchange process.

\section{TOPOTAXIAL HYDROTHERMAL ION EXCHANGE}

\section{TOPOTAXIAL CONVERSION OF CaClAp TO CaHAp.}

Hitherto, the hydrothermal method has been employed to prepare CaHAp single crystals in aqueous solutions at high temperatures $\left(750-800^{\circ} \mathrm{C}\right)$ in a close system [14]. Under these conditions, large single crystals have been grown with dimensions larger ( $8 \mathrm{~mm}$ length and $0.5 \mathrm{~mm}$ diameter) than those achievable using ordinary wet methods, however, the crystals exhibited a marked contamination with $\mathrm{CO}_{3}{ }^{2-}$. On the other hand, Yanagisawa et al. [15] have recently discovered that the topotaxial anionic replacement in the apatite structure also proceeds under alkaline hydrothermal conditions. The topotaxial replacement was initially determined on gem quality hexagonal prismatic $\mathrm{CaClAp}$ single crystals (2-4 $\mathrm{mm}$ long and $0.5-1 \mathrm{~mm}$ wide). Hydrothermal treatments were conducted using two different alkaline solutions of $\mathrm{KOH}(0.01-10 \mathrm{M})$ and $\mathrm{NaOH}(6.25$ and $8.25 \mathrm{M})$ as anion exchange media. These experiments were different from those carried out by Brenan [13] who used an ion exchange media saturated in $\mathrm{CaClAp}$. The reaction between the ion exchange media $\left(0.04 \mathrm{~cm}^{3}\right)$ and the crystals $(20 \mathrm{mg})$ was conducted in a platinum capsule $(30 \mathrm{~mm}$ length, $3.0 \mathrm{~mm}$ outer diameter and $0.15 \mathrm{~mm}$ thickness), which was sealed by welding shout with an electric arc. The treatments were conducted over the temperature range of $200-500^{\circ} \mathrm{C}$ for several reaction intervals (1-72 h), using a test tube type Stellite 25 vessel, and each run was carried out at a imposed pressure of $100 \mathrm{MPa}$ using water.

Yanagisawa et al. [15] have demonstrated that under these conditions, the complete conversion of $\mathrm{CaClAp}$ single crystals into CaHAp occurs at a temperature of $500^{\circ} \mathrm{C}$ for a reaction time as short as $12 \mathrm{~h}$ in a $6.25 \mathrm{M} \mathrm{KOH}$ solution. The effect of experimental variables such as: temperature, concentration of the ion exchange media and reaction time on the topotaxial ion exchange was investigated by XRD analyses of the reaction products. The ion exchange of $\mathrm{Cl}^{-}$by $\mathrm{OH}^{-}$was further achieved by using an ion exchange media with a concentration as high as $1 \mathrm{M}$ at temperatures above $300^{\circ} \mathrm{C}$ (Fig. 1).

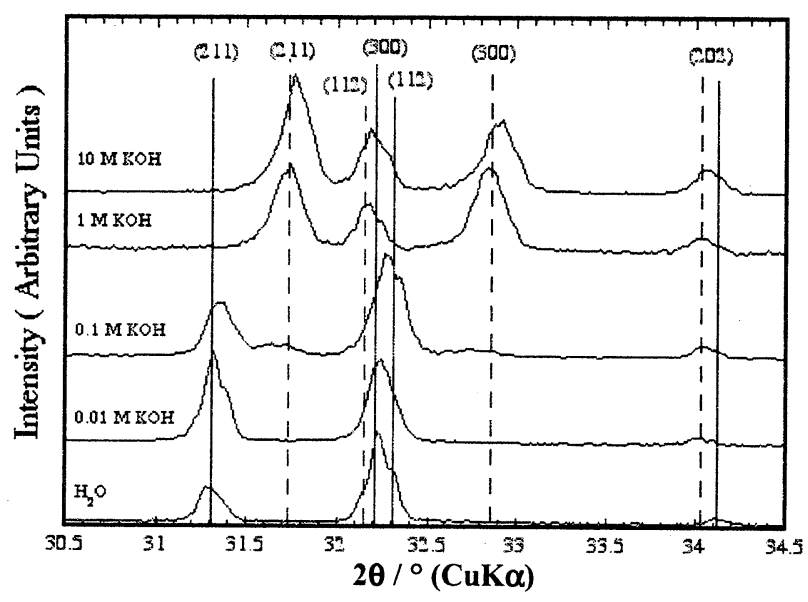

Fig. $1 \mathrm{X}$-ray diffraction patterns of the reaction products obtained at $500^{\circ} \mathrm{C}$ for $12 \mathrm{~h}$, which show the influence of the ion exchange media concentration. Solid line $=$ calcium chlorapatite dotted line $=$ calcium hydroxyapatite.

SEM observations were conducted to determine morphological aspects of the reaction products, revealed that the complete converted CaHAp did not exhibit significant change on the shape and dimensions, as seen in Fig.2c-f; in comparison with the unreacted $\mathrm{CaClAp}$ single crystal; Fig. 2 (a) and (b). Additional crystalline details on the converted CaHAp crystals were determined by Weissenberg X-ray 
Topotaxial Hydrothermal Anion Exchange in the Apatite Structure

precession photographs, and it was confirmed that the converted CaHAp crystals were single crystals with excellent quality. Based on these results, it was proposed that a high concentrated alkaline media promotes the topotaxial conversion of $\mathrm{CaClAp}$ singles crystals into CaHAp.

On the other hand, the effect of the alkaline metal $\left(\mathrm{K}^{+}\right.$or $\left.\mathrm{Na}^{+}\right)$incorporated in the ion exchange media on the microstructure of the reaction products is also showed in Figure 2. When the topotaxial replacement of $\mathrm{CaClAp}$ single crystals to $\mathrm{CaHAp}$ was carried out in $\mathrm{KOH}$ solution, a peculiar texture was observed on the reaction products. The texture consists of tiny elongated tunnels (10 $\mu \mathrm{m}$ length) formed parallel to $c$-axis on prism surfaces (Fig. 2c), and some cavities (diameter less than $0.5 \mu \mathrm{m}$ ) were observed on the cross section normal to the $c$-axis of the
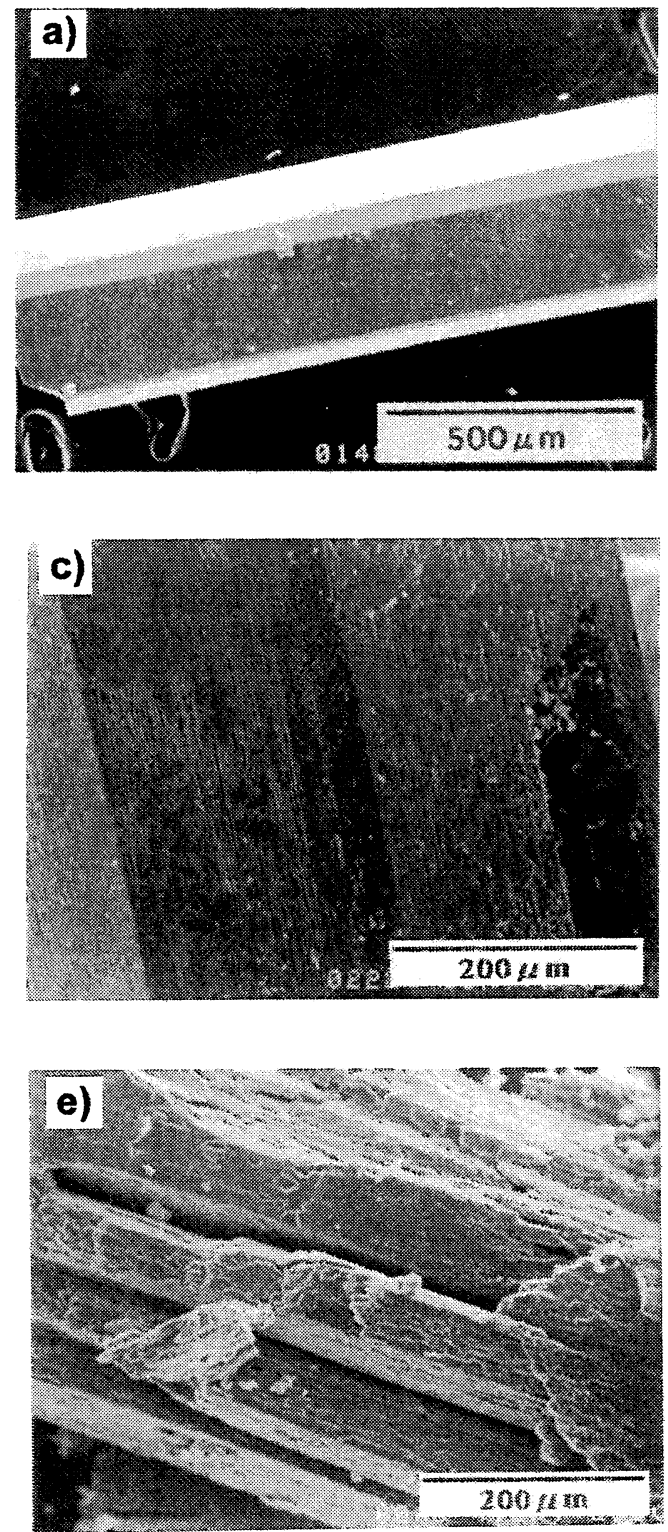

CaHAp crystal (Fig. 2d). These tunnels are a network that donot penetrate the crystals, however, draw a zigzag path course that allows the ion exchange media to penetrate inside the crystal. Although, the crystallographic transformation to CaHAp also proceeded in $\mathrm{CaClAp}$ crystals treated in $\mathrm{NaOH}$ solutions. The completely converted CaHAp crystals exhibited more corroded surfaces (Fig. 2e) in comparison with those found on the crystals treated in high concentrated $\mathrm{KOH}$ solutions $(10 \mathrm{M})$. In addition, the texture revealed also shows the formation of large irregular cavities, with a width of 0.5-2.0 $\mu \mathrm{m}$, randomly distributed on the fracture surface of the crystal perpendicular to $c$-axis. Some of the cross sections of these cavities were polygonal in shape.
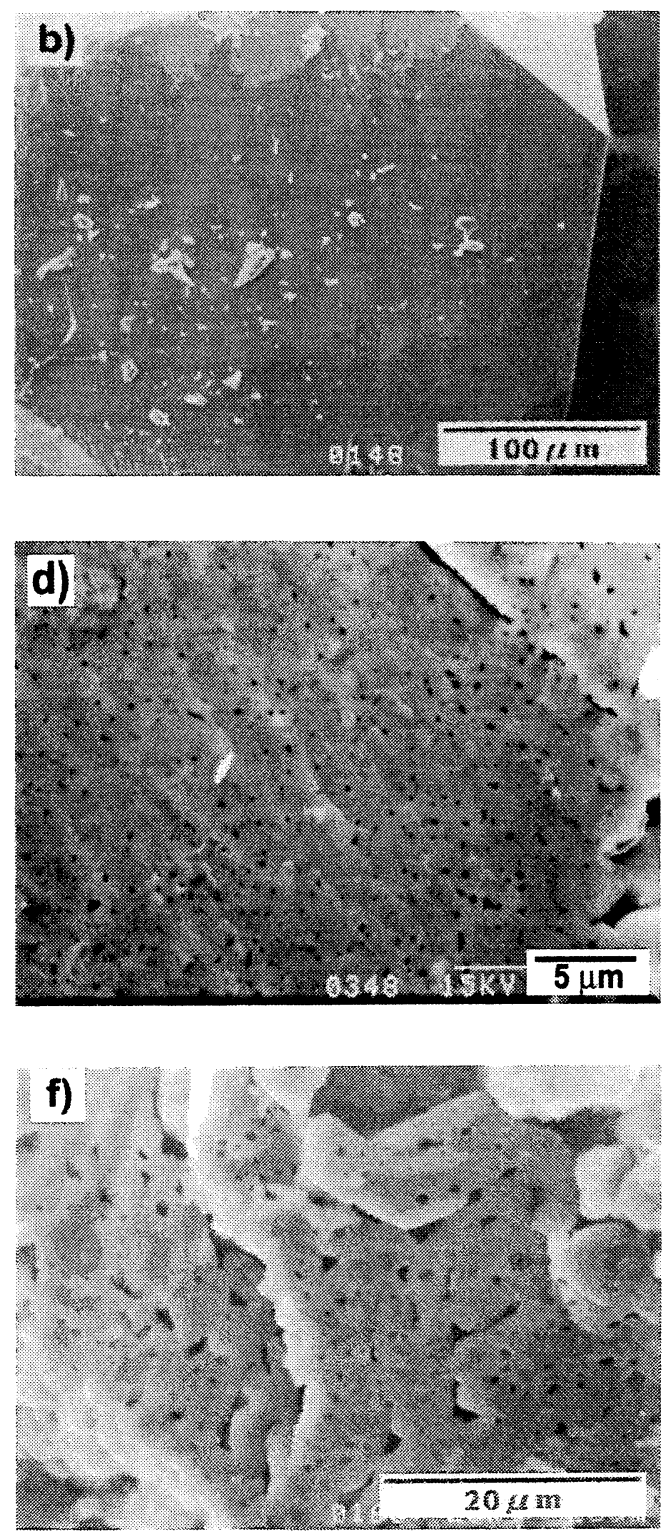

Fig. 2 SEM images of the prism surfaces and cross sections of the CaHAp crystals produced by the hydrothermal treatments of CaClAp crystals at $500^{\circ} \mathrm{C}$ for $24 \mathrm{~h}$ in $0.01 \mathrm{M}(\mathrm{a}, \mathrm{b})$ and $10 \mathrm{M} \mathrm{KOH}$ solution (c,d), and at $500^{\circ} \mathrm{C}$ for $12 \mathrm{~h}$ in $6.25 \mathrm{M} \mathrm{NaOH}$ solution (e,f). 
Rendon-Angeles JC, Yanagisawa K, Ishisawa N, Oishi S TOPOTAXIAL CONVERSION OF CaClAp AND CaHAp TO CaFAp.

Recently, a detailed investigation on the replacement of $\mathrm{F}^{-}$on $\mathrm{CaClAp}$ and $\mathrm{CaHAp}$ large single crystals was carried out under hydrothermal conditions by the present authors [16]. Both apatite single crystals were treated by the method described by Yanagisawa et al. [15], using a concentrated KF solution $(5 \mathrm{M})$, at $500^{\circ} \mathrm{C}$ for several reaction intervals, 2-96 $\mathrm{h}$ for $\mathrm{CaClAp}$ and 2-336 $\mathrm{h}$ for CaHAp. For the ion exchange reaction of $\mathrm{OH}^{-}$by $\mathrm{F}^{-}$, the large CaHAp single crystals $(2-4 \mathrm{~mm}$ large $0.5-1 \mathrm{~mm}$ width) were previously prepared from the $\mathrm{CaClAP}$ single crystals by the hydrothermal ion exchange reaction at $500^{\circ} \mathrm{C}$ for $48 \mathrm{~h}$, using a $6.25 \mathrm{M} \mathrm{KOH}$ solution as ion-exchange media.
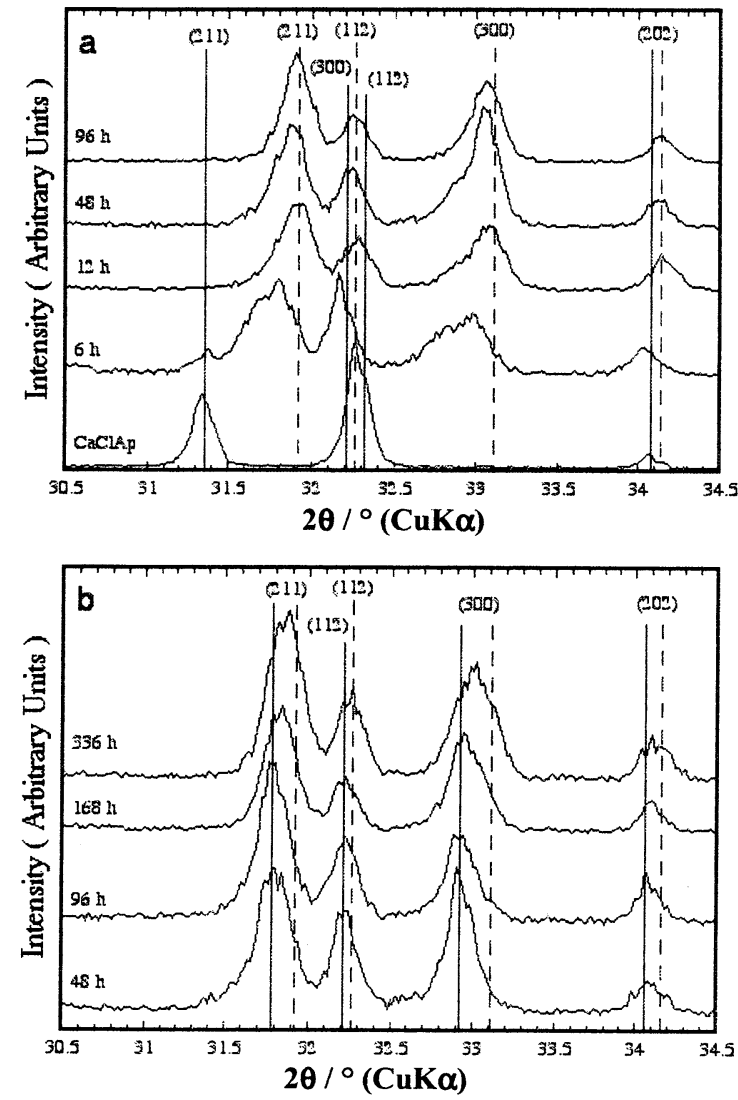

Fig. $3 \mathrm{X}$ ray diffraction patterns of the specimens obtained from the CaClAp (a) and CaHAp (b) crystals, after hydrothermal treatments in a $5 \mathrm{M} \mathrm{KF}$ solution at $500^{\circ} \mathrm{C}$ for various intervals: solid line $=$ chlorapatite or hydroxyapatite, dotted line $=$ fluorapatite .

In both cases the replacement of $\mathrm{Cl}^{-}$or $\mathrm{OH}^{-}$by $\mathrm{F}^{-}$in $\mathrm{CaClAP}$ or CaHAP single crystals, leads to the formation of a series of solid solutions in the ternary system, CaFAp-CaClAp-CaHAp, which was shown by the X-ray diffraction patterns of the specimens treated for several intervals (Figs. 3a and 3b). In both cases, the formation of a rich $\mathrm{F}^{-}$solid solution (SSCaFAp) occurred with the longest reaction time $(336 \mathrm{~h})$ by a progressive replacement of the original $\mathrm{Cl}^{-}$or $\mathrm{OH}^{-}$. When the CaClAp crystals were treated for $96 \mathrm{~h}$, the composition of the reaction product was determined to be $\mathrm{Ca}_{9.93} \mathrm{~K}_{0.07}\left(\mathrm{PO}_{4}\right)_{6} \mathrm{~F}_{1.85} \mathrm{Cl}_{0.03}(\mathrm{OH})_{0.05}$, while after the conversion of $\mathrm{CaHAp}$ to $\mathrm{CaFAp}$ for the longest reaction interval $(336 \mathrm{~h})$, the final phase obtained bore a small content of $\mathrm{Cl}^{-}$and $\mathrm{OH}^{-}$, $\mathrm{Ca}_{9.86} \mathrm{~K}_{0.14}\left(\mathrm{PO}_{4}\right)_{6} \mathrm{~F}_{1.16} \mathrm{Cl}_{0.16}(\mathrm{OH})_{0.54}$.

Regarding the morphological aspects of the reactions products, similar results to those reported for the replacement of $\mathrm{Cl}^{-}$with $\mathrm{OH}^{-}$in $\mathrm{CaClAp}$ single crystals were obtained. After the hydrothermal treatments, the original single crystals did not exhibit significant differences on their shape and dimensions, which implies that in both cases the conversion proceeds by the topotaxial ion replacement (Fig. 4 a and $b$ ). Preliminary evidence which indicate that a dissolution process occurs simultaneously during the ion exchange reaction is depicted by the partial formation of $\mathrm{CaF}_{2}$ single crystals that coat the reacted crystal surface. The rate of the ion exchange is mainly decreased by the presence of this $\mathrm{CaF}_{2}$ layer, because prevents the ion exchange media to penetrate inside the single crystal. This phenomenon explains the decrease of the release of $\mathrm{Cl}^{-}$and $\mathrm{OH}^{-}$from the raw CaHAp single crystals.
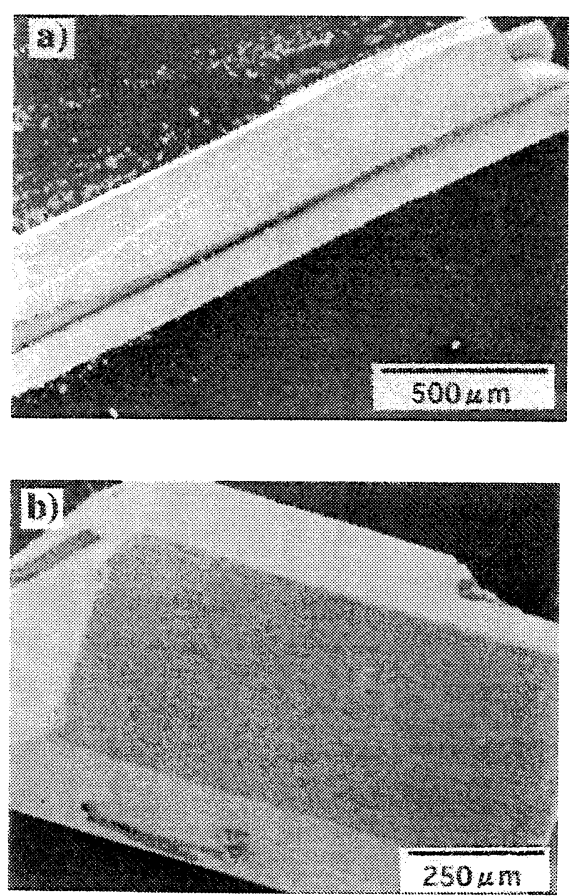

Fig. 4 Aspects of the prism surface of crystals converted by the ion exchange reaction in $\mathrm{CaClAp}$ (a) and $\mathrm{CaHAp}$ (b) crystals, hydrothermally treated at $500^{\circ} \mathrm{C}$ in a $5 \mathrm{M} \mathrm{KF}$ solution for $96 \mathrm{~h}$ and $336 \mathrm{~h}$, respectively. 
Topotaxial Hydrothermal Anion Exchange in the Apatite Structure

MISCELLANEOUS ASPECTS OF THE TOPOTAXIAL REPLACEMENT OF MCIAp BY MHAp AND CaFAp BY CaHAp.

The effect of the alkaline metal ions in the $\mathrm{M}$ site of the $\mathrm{M}_{10}\left(\mathrm{PO}_{4}\right)_{6} \mathrm{Cl}_{2}$ structure on the topotaxial replacement of $\mathrm{Cl}^{-}$by $\mathrm{OH}^{-}$was recently investigated. Experimental results obtained from strontium chlorapatite [ $\mathrm{SrClAp}]$ and barium chlorapatite [BaClAp] single crystals under alkaline hydrothermal conditions, have demonstrated that the topotaxial ion exchange is limited in these chlorapatite single crystals with large $(\mathrm{Sr}$, ionic radius of $0.113 \mathrm{~nm}$; and $\mathrm{Ba}$, ionic radius of $0.135 \mathrm{~nm}$ ) alkaline metal ions incorporated in the site $\mathrm{M}$ of the apatite structure [16]. The conversion to strontium hydroxyapatite [SrHAp] in $\mathrm{SrClAp}$ single crystals started at a temperature as low as $400^{\circ} \mathrm{C}$ in an alkaline $\mathrm{KOH}$ solution $(6.25 \mathrm{M})$. However, the complete conversion to SrHAp needed high temperature, $700^{\circ} \mathrm{C}$, for long reaction intervals up to $48 \mathrm{~h}$ (Fig 5a). The converted SrHAp crystals also retained their original shape and dimensions (Fig. 6a), although they had more corroded surfaces in comparison with those observed on the CaHAp crystals. Electron microprobe analyses showed that the completely converted SrHAP crystals included a small amount of $\mathrm{K}^{+}$and $\mathrm{Cl}^{-}$, and their composition was determined to be $\mathrm{Sr}_{9.96} \mathrm{~K}_{0.04}\left(\mathrm{PO}_{4}\right)_{6} \mathrm{Cl}_{0.18}(\mathrm{OH})_{1.76}$.

On the other hand, in the particular case of the $\mathrm{Cl}^{-}-\mathrm{OH}^{-}$ion exchange reaction on $\mathrm{BaClAp}$ single crystals, it was found that this reaction proceeded only at very high temperature, $800^{\circ} \mathrm{C}$, in comparison with that for $\mathrm{CaClAp}$ and $\mathrm{SrClAp}$ crystals, even in concentrated (10M) KOH solutions [17]. Under these severe hydrothermal conditions, the formation of a small amount of barium hydroxyapatite [BaHAp] was only detected by X-Ray diffraction analyses of the products (Fig. 5b). Observations of the polished cross section of the partially converted BaClAp crystals showed that the ion exchange proceeded by a progressive dissolution of the crystal surface in the ion exchange media. Microstructural obeservation of the crystals after the hydrothermal treatment showed the formation of a layer on the surface of the unreacted BaClAp part (Fig. 6b), and EMPA analyses conducted in this phase, showed that the layer had a composition nearly similar to the stoichiometric BaHAp $\left(\mathrm{Ba}_{9.94} \mathrm{~K}_{0.06}\left(\mathrm{PO}_{4}\right)_{6} \mathrm{Cl}_{0.04}(\mathrm{OH})_{1.90}\right)$. Furthermore, it was suggested that the texture of this layer, which is similar to those observed on the converted CaHAp and SrHAp single crystals, was also formed by the topotaxial ion exchange process. Simultaneously, this BaHAp layer was subsequently dissolved in the ion exchange media as ion species due to the high temperature of the treatment. Finally, this process leaded the formation of new small bulky single crystals, which also belonged to the hexagonal (space group $\mathrm{P}_{3} / m$ ) apatite structure with a composition of $\mathrm{Ba}_{4.8} \mathrm{~K}_{5.2}\left(\mathrm{HPO}_{4}\right)_{5.2}\left(\mathrm{PO}_{4}\right)_{0.8}(\mathrm{OH})_{1.76}$ (BaKHAp, Fig. 6b).

In previous works described above, the topotaxial replacement under hydrothermal conditions had been focussed to study isomorphic substitutions that imply the uptake of small ions, $\mathrm{F}^{-}$or $\mathrm{OH}^{-}$, and the release of larger ions, $\mathrm{Cl}^{-}$, in the apatite structure $[15,16]$. However, it was recently found that the topotaxial hydrothermal ion exchange mechanism was restricted in synthetic CaFAp crystals, when $\mathrm{F}^{-}$(ionic radius $0.132 \mathrm{~nm}$ ) were exchanged with $\mathrm{OH}^{-}$(ionic radius of $0.168 \mathrm{~nm}$ ). The conversion of CaFAp single crystals to CaHAp did not proceeded at temperatures below $600^{\circ} \mathrm{C}[18,19]$. Thus, the conversion to $\mathrm{CaHAp}$ occurred partially at $800^{\circ} \mathrm{C}$ in a $10 \mathrm{M} \mathrm{KOH}$ solution. The morphology of the reaction products was markedly different from those observed on the isomorphic topotaxial replacement reactions, namely $\mathrm{Cl}-\mathrm{OH}, \mathrm{Cl}-\mathrm{F}$ or $\mathrm{OH}-\mathrm{F}$. The ion exchange of $\mathrm{F}^{-}$ with $\mathrm{OH}^{-}$was further limited to occur at the prismatic end of the crystals (Fig. 7a). A characteristic texture consisting of deep holes was obtained as the ion exchange reaction gradually proceeded. R.A. Young have reported that the CaFAp is locally dissolved in acidic media from the prismatic end of the crystals [20]. The partial dissolution of the CaFAp crystals under alkaline hydrothermal conditions resulted in the formation of formation of holes during the conversion to CaHAp. Furthermore, this phenomenon leaded
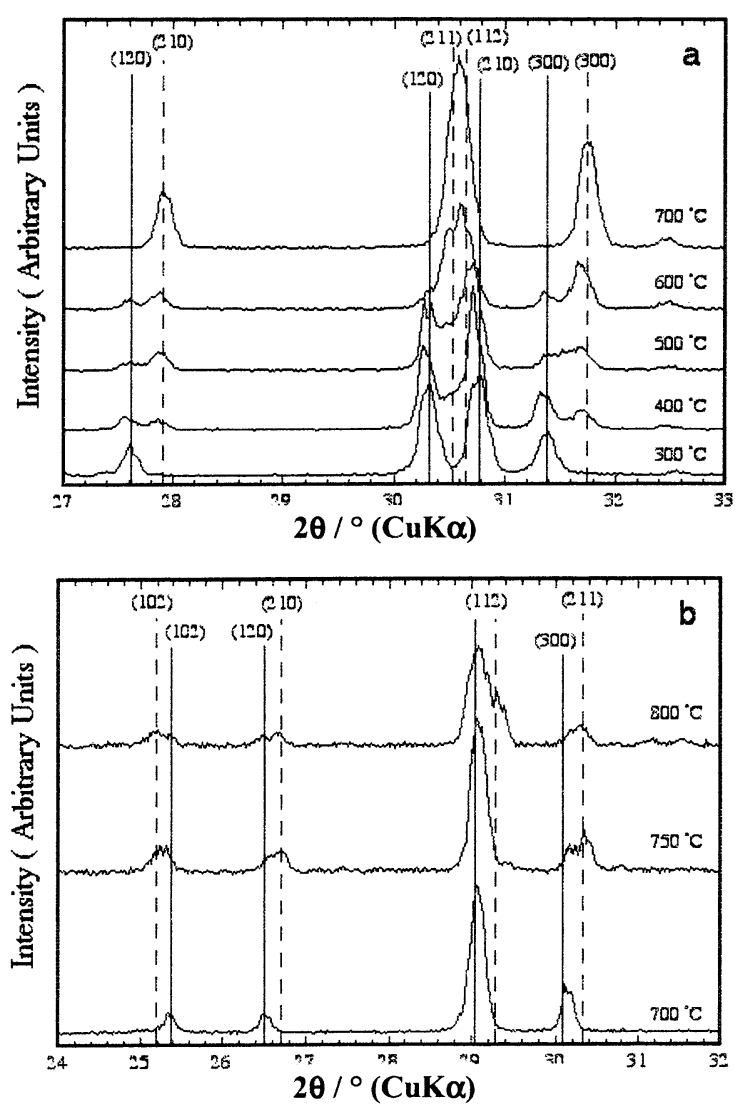

Fig. $5 \mathrm{X}$-ray diffraction patterns of the specimens obtained from the SrClAp (a) and BaClAp crystals, treated under hydrothermal conditions in $6.25 \mathrm{M}$ and $10 \mathrm{M} \mathrm{KOH}$ solutions for 48 at different temperatures, respectively. Solid line $=\mathrm{SrClAp}$ or $\mathrm{BaClAp}$, dotted line $=$ SrHAp or BaHAp species. 

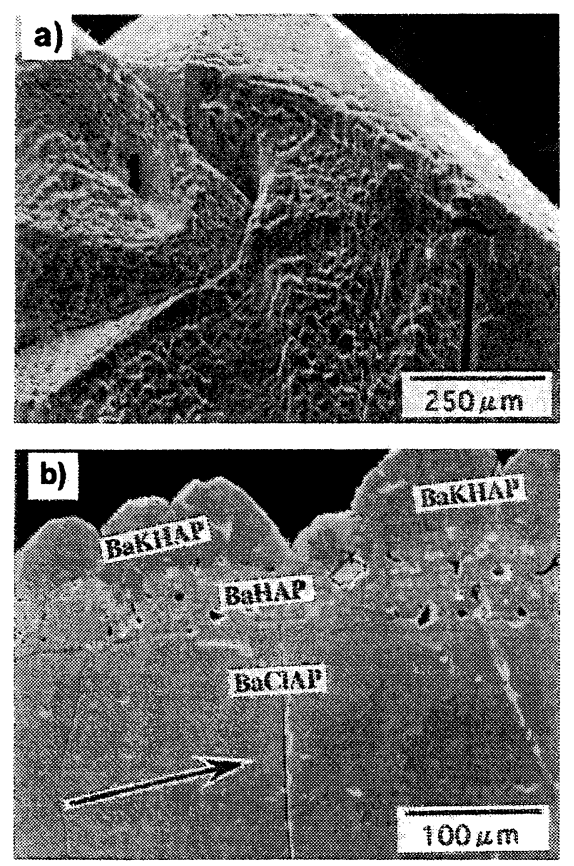

Fig. 6 Aspects of the topotaxially converted SrHAp crystals (a) at $700^{\circ} \mathrm{C}$ for $48 \mathrm{~h}$ in $6.25 \mathrm{M}$ $\mathrm{KOH}$ solution, and partially converted BaHAp (b) at $800^{\circ} \mathrm{C}$ for $48 \mathrm{~h}$ in $10 \mathrm{M} \mathrm{KOH}$ solution. The arrow on the photograph indicates the direction of the $c$-axis.
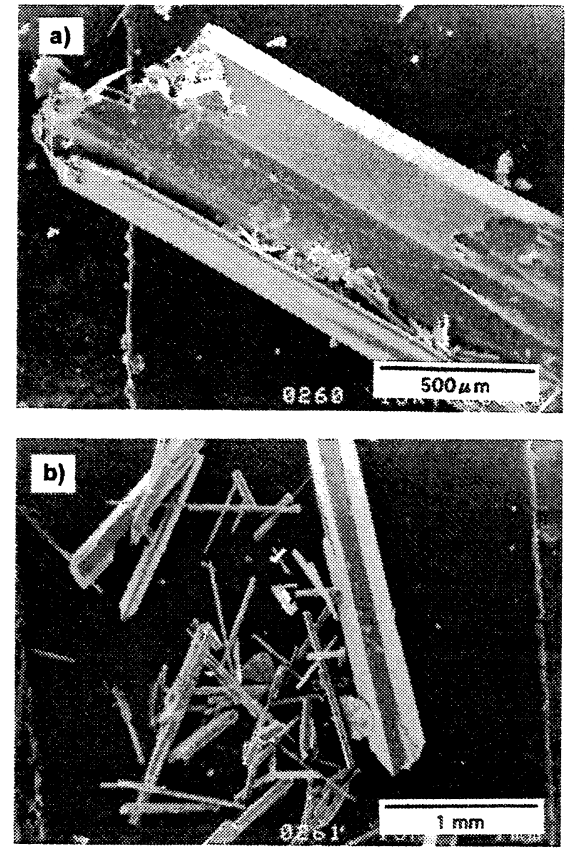

Fig. 7 SEM images of partially reacted CaFAp single crystals (a) and the completely converted CaHAp small crystals (b). Both crystals were obtained by hydrothermal treatment at $800^{\circ} \mathrm{C}$ for 6 $\mathrm{h}$ in a solution $10 \mathrm{M} \mathrm{KOH}$. the formation of acicular CaHAp single crystals with a chemical composition of $\mathrm{Ca}_{10}\left(\mathrm{PO}_{4}\right)_{6} \mathrm{~F}_{0.5}(\mathrm{OH})_{1.5}$ (Fig. $7 \mathrm{a})$. In accordance with the previous results reported by Brenan [13], the compensation of the lattice volume variation might induce the formation of microcracks, resulting in the fracture of the acicular crystals from the CaFAp original crystals (Fig. 7b). This hypothesis is supported by some experimental facts, i) The new acicular CaHAp single crystals were not formed by a recrystallization process which is observed in ordinary hydrothermal treatments with a temperature gradient. ii) The acicular crystals obtained by the ion exchange reaction were faceted but they often had huge grooves along the $c$-axis, which were seldom produced by a typical dissolution precipitation process [21].

\section{TEXTURE OF THE TOPOTAXIAL CONVERTED SINGLE CRYSTALS.}

Many works have been conducted to determine the solubility and dissolution kinetics of CaHAp, CaClAp and their related solid solutions [22]. Several of these studies were performed at low temperature $\left(<37^{\circ} \mathrm{C}\right)$ with atmospheric pressure, and showed that the stoichiometric dissolution of the apatites proceeded in buffered media with a $\mathrm{pH}$ range of 4.9-7.5. However, information related with the formation of a peculiar texture as a result of the dissolution process was not reported yet. In contrast, the acidic dissolution process in caries attack on human tooth enamel also takes place preferentially along the crystals $c$-axis of the apatite structure $[11,23,24]$. Similar observations were given by Young [20] on CaHAp single crystals exposed to acid solutions. The acidic dissolution was strongly anisotropic, producing various tunnels parallel to the $c$-axis.

Any data on the dissolution of the apatites under alkaline hydrothermal conditions have not been yet reported [14]. However, according to the review above mentioned, it is likely that the surface features of the converted CaHAp (Fig. 2), SSCaFAp (Figs. 3 and 4), SrHAp (Fig. 5) or BaHAp (Fig. 6) crystals, might be formed by dissolution of the apatites under the alkaline hydrothermal treatment. The holes or tunnels formed inside the crystals are not etch pits developed during dissolution, because they do not penetrate the crystals and the holes are very homogeneous in size.

On the other hand, the variation of the lattice constants associated with the ion exchange is shown in Table I. Form these data, it is clear that the ion exchange of $\mathrm{Cl}-\mathrm{OH}$ or $\mathrm{Cl}-\mathrm{F}$, involves a large shrinkage along the $a$-axis and a slight expansion along the $c$-axis of the hexagonal lattice. This fact is important to consider the relationship between the texture developed on the converted crystals and the shrinkage produced as a result of the hydrothermal topotaxial replacement. In order to maintain the single 
Topotaxial Hydrothermal Anion Exchange in the Apatite Structure

Table 1 Lattice constants of apatites and variation of lattice constants by ion exchange.

\begin{tabular}{|c|c|c|c|c|c|c|c|}
\hline \multicolumn{2}{|c|}{$\begin{array}{c}\text { chlorapatite lattice } \\
\text { constants }\end{array}$} & \multicolumn{2}{|c|}{$\begin{array}{c}\text { hydroxyapatite lattice } \\
\text { constants }\end{array}$} & \multicolumn{2}{|c|}{$\begin{array}{l}\text { fluorapatite lattice } \\
\text { constants }\end{array}$} & \multicolumn{2}{|c|}{$\begin{array}{l}\text { Lattice constant } \\
\text { variation }\end{array}$} \\
\hline$a(\mathrm{~nm})$ & $c(\mathrm{~nm})$ & $a(\mathrm{~nm})$ & $c(\mathrm{~nm})$ & $a(\mathrm{~nm})$ & $c(\mathrm{~nm})$ & $\Delta a(\mathrm{~nm})$ & $\Delta c(\mathrm{~nm})$ \\
\hline 0.9641 & 0.6771 & 0.9424 & 0.6881 & & & $-0.0217^{a}$ & $0.0110^{a}$ \\
\hline \multirow[t]{2}{*}{0.9641} & 0.6771 & & & 0.9386 & 0.6884 & $-0.0255^{b}$ & $0.0113^{b}$ \\
\hline & & 0.9424 & 0.6881 & 0.9386 & 0.6884 & $-0.0038^{c}$ & $0.0003^{c}$ \\
\hline
\end{tabular}

Note. The lattice variation corresponds to then following ion exchange in calcium apatite host ${ }^{a} \mathrm{Cl}-\mathrm{OH}$,

${ }^{b} \mathrm{Cl}-\mathrm{F}$ and ${ }^{c} \mathrm{OH}-\mathrm{F}$.

crystal structure and the original dimensions of the crystals after the conversion, the dimensional variation must be compensated by the formation of holes along the $c$-axis inside the converted crystals [15]. This inference is supported by the present authors [18]. They found that any holes were formed during the exchange of $\mathrm{F}^{-}$in CaFAp single crystals by $\mathrm{OH}^{-}$under alkaline hydrothermal conditions, because this peculiar type of conversion implies an expansion of the crystal lattice along either $a$ and $c$-axes.

\section{HYDROTHERMAL TOPOTAXIAL ION EXCHANGE MECHANISM.}

The ion exchange mechanism for ionic and cationic species in the solid state has been reported to occur in the apatite structure by atomic diffusion even under hydrothermal conditions $[13,20]$. Several authors have demonstrated that anion diffusion in the apatite structure occurs essentially parallel to the $c$-axis, because the lattice exhibits a preferential alignment of the anions, $\mathrm{OH}^{-}, \mathrm{Cl}^{-}$or $\mathrm{F}^{-}$; along the $\mathrm{X}$-channels incorporated within the calcium ion triangles. Tse et al.[25] suggested that $\mathrm{OH}^{-}$ion motion along the columns is relatively easy, whereas motion between adjacent columns should be less likely. These authors considered that the ion motion is promoted by an interaction between ions and structural defects (vacancies) in the solid state.

Concentration profiles determined on the partially converted crystals (Fig. 8) under hydrothermal conditions, exhibited a markedly difference on the concentration of $\mathrm{Cl}^{-}$along the direction in which the ion exchange proceeds. This is clearly indicated by two plateaus separated by a sharp boundary between the converted CaHAp and the unreacted $\mathrm{CaClAp}$ part (Fig 8a). Furthermore, the reaction homogeneously proceeded at both $a$ and $c$ axes. These results suggest that the ion exchange mechanism under hydrothermal conditions can not be associated with the solid state ion exchange mechanism. Yanagisawa et al. [15] have independently proposed a mechanism based on dissolution-precipitation of clusters. A dissolution and deposition process is expected to occur during the hydrothermal ion exchange. This inference agrees with the fact that the converted crystals of CaHAp or SrHAp include a slight amount of the alkaline metal ions $\left(\mathrm{K}^{+}\right.$or $\left.\mathrm{Na}^{+}\right)$used as a reaction medium. The dissolved species under these conditions must be clusters with a size much larger than ionic species, because any new crystals were formed in the capsule by recrystallization and the conversion occurred in the original crystals. The dissolution of the original $\mathrm{CaClAp}$ crystals in alkaline solutions and formation of clusters must result in the ion exchange of $\mathrm{Cl}^{-}$at the surface of the clusters by $\mathrm{OH}^{-}$. Furthermore, the small tunnels were formed in the crystals as the topotaxial ion exchange proceeded, allowing the exchange of exhausted reaction media by fresh one so that the topotaxial replacement process continued inside the crystal. The formation of tunnels is retarded when large metal ions are located in the $\mathrm{M}$ site of the apatite structure $\left(\mathrm{M}_{10}\left[\mathrm{PO}_{4}\right]_{6}[\mathrm{X}]_{2}\right)$, because the shrinkage of the apatite lattice with large metal ions by the ion exchange of $\mathrm{Cl}^{-}$with $\mathrm{OH}^{-}$is smaller. Thus, the exchange of $\mathrm{Cl}-\mathrm{OH}$ was limited in $\mathrm{BaClAP}$ and that in $\mathrm{SrClAp}$ crystals proceeds on two steps, the first step is related with the formation of an intermediate solid solution in the SrClAp-SrHAp system, and finally the SrHAp phase was produced by a dissolutiondeposition process (Fig. 8b).

In the apatite structure, the topotaxial exchange ability was found to depend not only on the apatite structures consisting of various anions and cations, but also the ions which are incorporated into the apatite structure by the ion exchange. The topotaxial ion exchange proceeds very fast when large anions in the 
Rendon-Angeles JC, Yanagisawa K, Ishisawa N, Oishi S apatite structure are replaced by small anions. Furthermore, apatite structure incorporating small metal ions exhibits the high topotaxial ion exchange ability. These results suggest that calcium bromide apatite $(\mathrm{CaBrAp})$ with a large anion than $\mathrm{Cl}^{-}$may be topotaxialy exchanged to CaHAp or CaFAp, as well as, cadmium chlorapatite (CdClAp) and lead chlorapatite $(\mathrm{PbClAp})$ with a smaller cation than $\mathrm{Sr}$ also may undergo the topotaxial anion exchange of $\mathrm{Cl}^{-}$ by $\mathrm{OH}^{-}$.
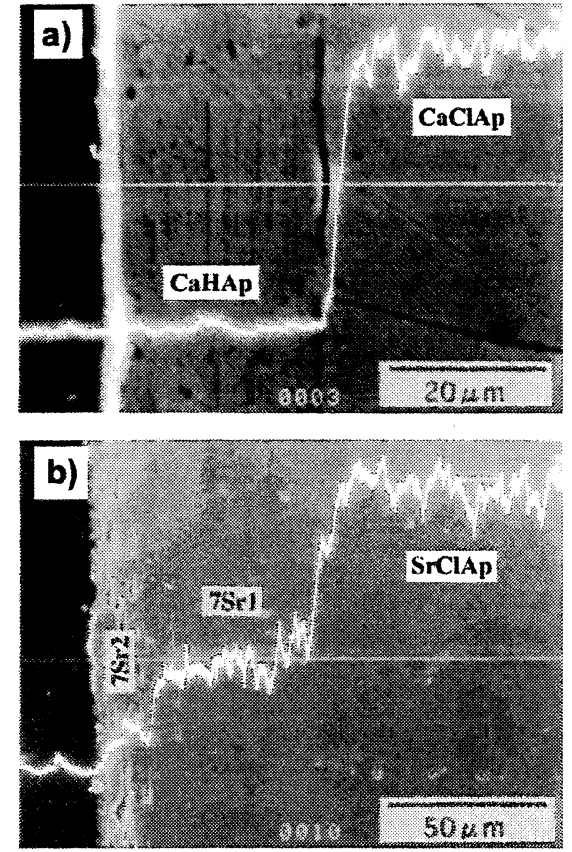

Fig. 8 SEM images of the cross section of the crystals parallel to the $\mathrm{c}$ axis and results of $\mathrm{Cl}^{-}$line analyses, (a) $\mathrm{CaClAp}$ single crystals treated at $500^{\circ} \mathrm{C}$ for $3 \mathrm{~h}$ in $6.35 \mathrm{KOH}$ solution, (b) SrClAp crystals treated at $700^{\circ} \mathrm{C}$ for $12 \mathrm{~h}$ in $6.25 \mathrm{M} \mathrm{KOH}$ solution.

\section{REFERENCES}

1. H. G. Schaeken, R. M. H. Verbeek, F. C. M. Driessens and H. P. Thun, Bull. Soc. Chim. Belg. 84, 881 (1975).

2. K. Sudarsanan, P. E. Mackie, and R. A. Young, Material Research Bulletin. 7, 1331 (1972).

3. E. J. Young, A. T. Myers, E. L. Munson, N. M. Conklin, Proc. U.S. Geol. Survey Prof., paper 650-D, D84 (1969).
4. T. S. B. Narasaraju and D. E. Phebe, J. Mater. Sci. 31, 1 (1996).

5. J. M. Hughes, M. Cameron and K. D. Crowley, Amer. Mineralogist, 75, 295(1990).

6. C. Latil and R. Maury, Bull. Soc. Fr. Minéral Cristallogr. 100, 246 (1977).

7. F. C. M. Driessens, R. M. H. Verbeeck and P. Z. Kiekens, Anorg. All. Chemie, 504, 195 (1983).

8. G. C. Maiti and F. Freund, Journal of Inorganic Nuclear Chemistry, 43, 2633 (1981).

$9 . \quad$ R. Z. Legeros, O. R. Trautz, J. P. Legeros and E. Klein, Bulletin de la Société, Chimique de France, Special Issue, 1712 (1968).

10. M. Massuyas, J. C. Trombe. G. Bonel and G. Montel, Bull. Chem. Soc. Jpn. 7, 2308 (1969).

11. J. C. Elliot and R. A. Young. Nature, 214, 904 (1967).

12. K. Sudarsanan and R. A. Young, Acta of Crystallography, B34, 1401 (1978).

13. J. Brenan, Chemical Geology, 110, 195 (1994).

14. W. Eysel and D. M. Roy, J. Cryst. Growth, 20, 245 (1973).

15. K. Yanagisawa, J. C. Rendon-Angeles, N. Ishizawa and S. Oishi, Amer. Mineralogist, 84, 1861 (1999).

16. J. C. Rendón-Angeles, K. Yanagisawa, N. Ishizawa and S. Oishi, Chemistry of Materials, 12, 2143 (2000).

17. J. C. Rendón-Angeles, K. Yanagisawa, N. Ishizawa and S. Oishi, J. of Solid State Chemistry, 154, 569 (2000).

18. J. C. Rendón-Angeles, K. Yanagisawa, N. Ishizawa and S. Oishi, J. of Solid State Chemistry, 151, 65 (2000).

19. J. C. Rendón-Angeles, K. Yanagisawa, N. Ishizawa and S. Oishi, Proc. ISCTR , 151, 65 (2000).

20. R. A. Young, Proceedings of the International Congress of Phosphorous Compounds, 73 (1980).

21. J. R. Farver and B. J. Giletti, Geochimica et Cosmochimica Acta, 53, 1621 (1989).

22. T. S. B, Narasaraju, K. K. Rao and U. S. Rai, Canadian Journal of Chemistry, 57, 1919 (1979).

23. D. Langdon, E. Dykes and R. W. Fernhead, Colloque International CNRS, Physico-Chimie et Crystallographie des Apatites d'Intérêt Biologique, Paris, No. 230, 381 (1975).

24. J. Arends, P. J. Van Der Berg and W. L. Jongebloed, Colloque International CNRS, Physico-Chimie et Crystallographie des Apatites d'Intérêt Biologique, Paris, No. 230, 389 (1975).

25. C. Tse, D. O. Welch and B. S. H. Royce, Calcified Tissue Research, 13, 47 (1973) 